\title{
Optimization of geometry of the sealing cuff of the piston of volumetric oil and gas hydraulic aggregates
}

\author{
Oleg Dushko ${ }^{1}$, Vladimir Perfilov ${ }^{1, *}$, and Vladimir Yaroshik ${ }^{1}$ \\ ${ }^{1}$ Volgograd State Technical University, Oil and Gas Constructions Department, Avenue V.I. Lenin, 28, 400005, Volgograd, Russia
}

\begin{abstract}
The use of modern sealing elements of volumetric hydroaggregates in the oil and gas industry is hampered by lack of scientifically based constructive decisions. The implementation of this complex and urgent challenge is possible due to optimization of geometry of the elastic seal (cuff) by criterion of uniform distribution of contact tensions on all its length that it will promote uniform wear of the seal. It is possible to manage this process change of initial geometry of the cuff.
\end{abstract}

\section{Introduction}

Increase the reliability and durability of volumetric hydroaggregates is particularly acute especially now. First of all it concerns the equipment working in the oil and gas industry, where separate components and aggregates are exposed to simultaneous influence of high contact tensions and temperatures, containing aggressive abrasive environments, that substantially reduces a resource and reliability of work not only separate components and aggregates, but also in whole oilextracting complexes [1,2].

From operating experience of machines and mechanisms it is known that reliability of any technical system directly depends on reliability of separate components and details constituting this system. Due to the above, one of the main directions of development of the domestic industry is to increase the wear resistance and durability of machines and equipment, repeated decrease in repair work is. Particularly relevant this question in oil-extracting and petrochemical industries in relation to the sealing elements and friction pairs of volumetric hydroaggregates[3-6].

In the process of pumping of the oil products, drilling mud containing solid-phase particles there is an abrasive wear of surfaces of friction pairs, which that conducts to a leakage of liquid and reduce a resource of work of the equipment [6-8]. Working capacity, reliability, fire and environmental safety of production objects significantly depends on perfection, reliability and resource of work of heavy-duty friction pairs, and condensed elements of different function. On sea oil and gas complexes, and also on machine-building, chemical, petrochemical, some overworking and other enterprises volumetric hydroaggregates and automated pneumatic test facilities, which basis is constituted by driving pumps of direct reciprocating action gain distribution. Volumetric aggregates with mechanical and pneumatic actuator are effective, first of all, when using in objects with increased fire and environmental danger [9-14].

\section{Main part}

The weakest spot, of volumetric hydroaggregates, especially in case of 50-150 MPa, consolidations which often use liquids with limited greasing properties are. For example, drilling of oil and gas wells is impossible without system of circulation of drilling mud and its basis - drilling pumps. Mud pumps - volumetric hydraulic machine - are characterized by high capacity and high hydraulic pressure.

On installations of OAO "Volgograd plant of drilling equipment" capacity of pumps reaches $600 \mathrm{~kW}$, and the pressure - $25 \mathrm{MPa}$; on OAO "Uralmash" - respectively $950 \mathrm{~kW}$ and $40 \mathrm{MPa}$ (unique installations for superdeep drilling are not considered). Cylinder-piston group of pumps works in hard conditions - in the presence of solid particles (abrasive) in drilling fluid, which temperature reaches $100{ }^{\circ} \mathrm{C}$. Such conditions predetermine limited service life of pump seals, which when drilling of deep wells (3000 meters or more) sometimes are constituted by only 40 hours. It forces to contain as a part of the drilling rig at least two pumps (one in a hot allowance). In the same time conditions the equipment for forcing of cementing, clay and other trade and squeezing liquids in oil and gas wells in process of their drilling or repair of UNB-125x63 (analogue of CA-320) works.

Thus, increase of resource of cuff to a resource of other basic elements of system will allow to create reliable and economical hydroaggregate that, finally, will lead to increase in overall performance of all processing equipment in general [15-19]. The solution of this complex problem is possible due to optimize of geometry of an elastic seal (cuff) by criterion of uniform distribution of contact tensions on all its length that will promote uniform wear of the seal $[20,21]$. It is possible

\footnotetext{
Corresponding author: vladimirperfilov@mail.ru
} 
to manage this process change of initial geometry of the cuff.

The effective analytical method of determination of tension and deformations in a cuff allowing to receive the required solution of a task of optimization for real time was developed for search of the optimal solution. The essence of this method consists in determination of the intense-deformed condition of the cuff and contact tensions in cuff in case of its interaction with the cylinder for the set any initial geometry of the cuff and pressure of working liquid in the cylinder.

For calculation of intense-deformed condition of an elastic seal of the piston working course when on volumetric hydromachine the piston 1 under influence of force $\mathrm{F}$ creates working pressure $\mathrm{p}$ repumped liquid in the cylinder 4 (Fig. 1). Sealant 2, prevulcanized to the piston, interferes with penetration of working liquid 3 into a gap at the internal surface of the cylinder 4 . At the same time sealant is affected by hydrostatic pressure $p$ of liquids and friction forces on the contact surface "sealant - cylinder".

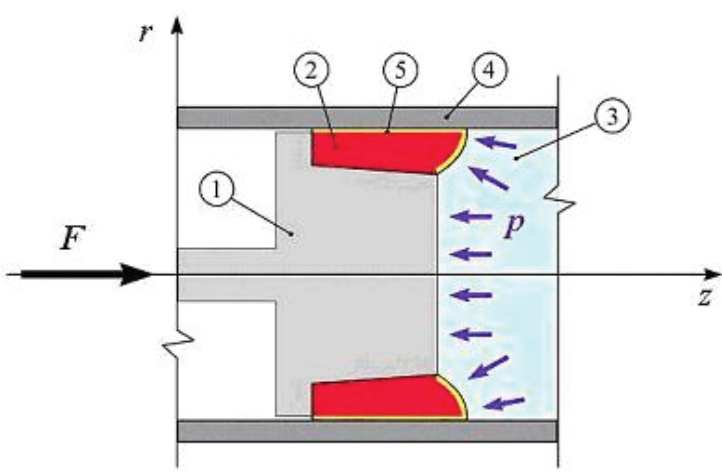

Fig. 1. Working piston stroke: 1 - metal core; 2 - elastic sealant; 3 - working liquid; 4 - cylinder; 5 - modified layer

For creation of preliminary consolidation, a forward part of a sealant (a bell-shaped part) is executed with a diameter big the internal diameter of the cylinder plug. It is necessary to emphasize that the seal material (rubber mixture) is uniform and isotropic in all amount, except area of contact with the cylinder. Here the surface layer 5 , for increase in a resource, can be modified - in rather thin surface layer module of elasticity significantly higher than the module of elasticity of the main amount of material of the cuff [22-26].

We consider that for the solution of an objective there is possible an application of a mathematical apparatus and methods of the linear theory of elasticity. It follows from the fact that, first, the sealant is in tension (Fig. 1), axisymmetric concerning an axis $\mathrm{z}$, and tensions and deformations changes only along two coordinate axes $\mathrm{z}$ and $\mathrm{r}$, and secondly, deformations of sealant are small $(\varepsilon<10 \%)$ owing to what communication between tensions and deformations can be described by a linear dependence (Hooke's law).

During the carried-out calculation, the intensedeformed condition of a cuff and contact tension "cuff cylinder" for the set any initial geometry of a cuff and working pressure of liquid is determined that forms the basis of the solution of a task of optimization of geometry of a sealant.

In Fig. 2 system of geometry of the cuff and loading for working piston stroke in system of coordinates z-r is shown, and in Fig. 3 settlement scheme of geometry of the cuff in not deformed condition is shown.

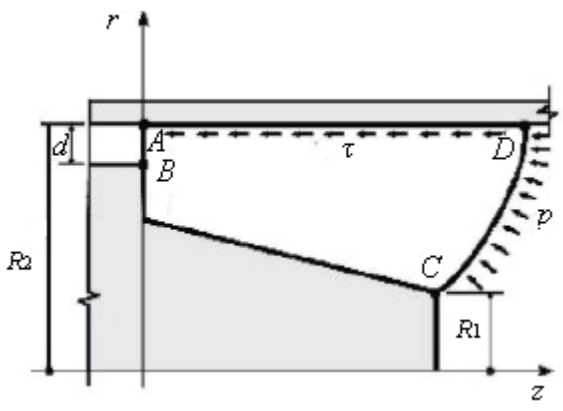

Fig. 2. Cuff geometry for the working course

For definition of the intense-deformed condition of a sealing cuff the known method of function of tension and designations, standard for the theory of elasticity, and the rule of signs for tension and movements is used. However, for the solution of a task the function of tension has been entered. Let's note that boundary conditions on each contour are met approximately: their exact compliance is carried out only in separate points of a contour which number can be any. At the same time increase in these points leads to increase accuracy of solution of a task (fig. 3).

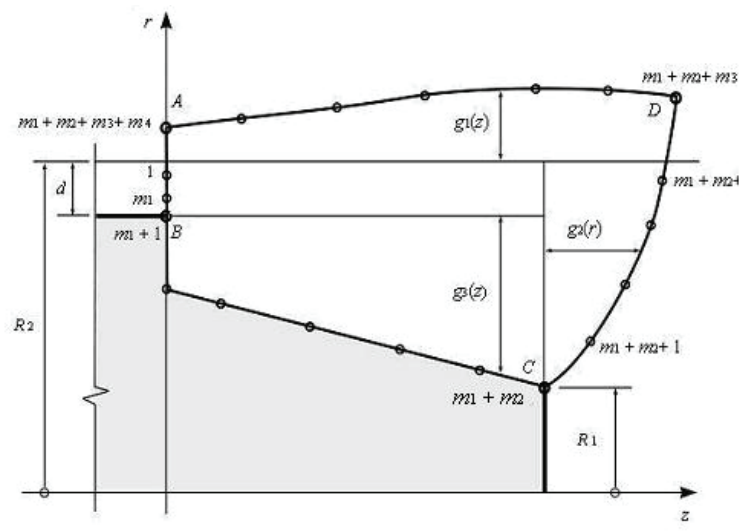

Fig. 3. Initial geometry of the cuff in a free state

The received decision precisely satisfies to all equations of the theory of elasticity at the confidant, as much as exact, performance of boundary conditions, and comes down to the solution of system of the linear algebraic equations. The order of system of equations is equal to the doubled number of points of contour for satisfaction to boundary conditions.

Contact tangent tension is provided by power series through unknown coefficients which are defined from balance conditions.

Function of purpose defines compliance of the decision top optimum and is accepted in the form of weighted combination of the decisions determining the sum of squares of deviations of contact tensions from an 
average at various stages of attrition of the surface. At the same time function of purpose gives chance to define an optimal configuration of the cuff for the most uniform distribution of contact tensions in work process and deleting of material.

In Fig.4 initial optimal configuration of the cuff (curve 3 - in full-scale, curve 2 - in increased scale) and the corresponding distribution of contact tensions (curve 1) without cuff material attrition in work process is shown.
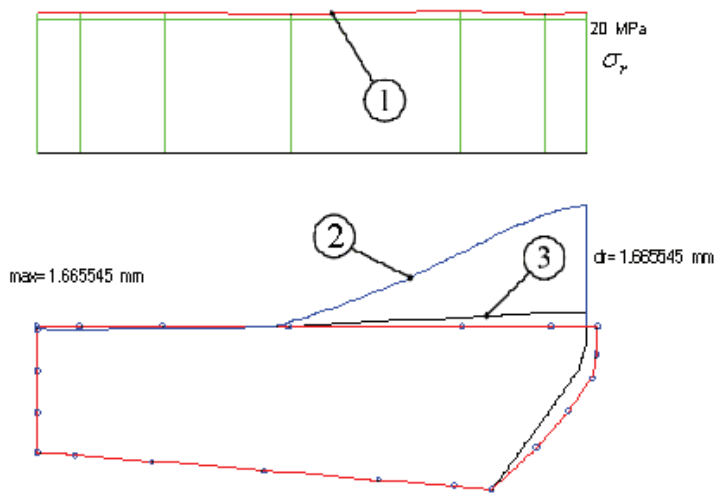

Fig. 4. Optimal configuration of cuff without considering erasure: 1 -distribution of contact tensions; 2 - optimal geometry of cuff in increased scale; 3 - optimal geometry of cuff in full-scale.

In Fig. 5 initial optimal configuration of the cuff for receiving the maximum possible uniform distribution of contact tensions in work process at her deleting on depth of $0,5 \mathrm{~mm}$ (curve 3 - in full-scale, curve 4 - in increased scale) and the corresponding distribution of contact tensions (curve 1 - beginning of work, curve 2 - erased surface).

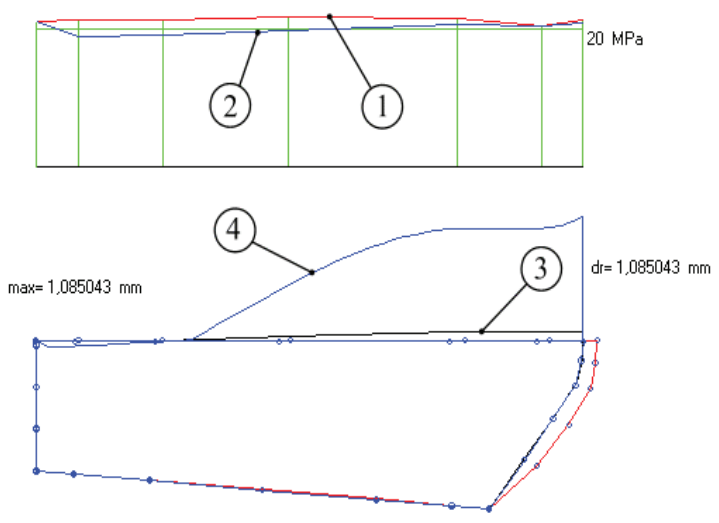

Fig. 5. Optimal configuration of cuff subject to erasure: 1 distribution of contact tensions at beginning of work; 2 distribution of contact tensions after attrition; 3 - optimal geometry of cuff in full-scale; 4 - optimal geometry of cuff in increased scale.

\section{Conclusions}

Thus, it is possible to manage process of wear of an elastic sealant by change of its initial geometry.
Calculation of initial optimum, from the point of view of uniform wear, surface geometry of seal can be performed using a mathematical apparatus and methods of linear theory of elasticity. [27, 28].

Modification of sealants more than by 5,6 times raises a resource of pistons of mud pumps, and universal consolidations increase efficiency of hydropneumatic devices of reciprocating action with high and ultrahigh pressure, including several times a resource of pistons of mud pumps (when testing on the stand) [29,30]. Reliability of elaborated provisions, conclusions and recommendations is confirmed with practice of designing, the solution of analytical tasks on the computer, testing at stands with imitation of severe conditions of operation, production and approbation of samples as a part of the installations working in actual practice.

\section{References}

1. O.V. Dushko, V.I. Pindak, A.D. Polikarpov, A.V. Shcherbin, Possibilities of increase the durability of oil fields pump units and decrease their consumption, Geology, drilling and development of oil fields of Prikaspiya and the Caspian sea, Iss. 61, Pp. 182-191 (2003)

2. O.V. Dushko, Tribology of seals of oil and gas volume hydrounits (Volgograd: publishing house of VolgGASU, 2005)

3. H. Yuan, J. Guo, Z. Su, Y. Sun, J. Qi, Research on reliability of domestic drilling mud pump pistoncylinder linerfriction pair, Zhongguo Jixie Gongcheng, Vol. 24, No. 11. Pp. 1425-1430 (2013)

4. E.F. Romanenko, V.I. Kolmykov, Analysis of geological exploration mud pumps component wear and damage, Chemical and Petroleum Engineering, Vol. 49, No. 11-12, Pp. 811-815 (2014)

5. E.K. Isakaev, V.B. Mordynskii, A.S. Tyuftyaev, Y. M. Avilkin, V. A. Katarzhis. Increasing the service life of rapidly wearing components of mud pumps, Welding International, T.26, No.1, Pp.40-44 (2012)

6. A.A. Asheichik, V.L. Polonsky, Experimental study of elastomers and polymers for oil industry (St. Petersburg, 2015)

7. O.V. Dushko, V.I. Pindak, Loading and wear resistance of rubber piston drilling and oil fields pumps, Construction of oil and gas wells on land and at sea, No. 5, Pp. 23-25 (2014)

8. V. Spitas, C. Spitas, G.A. Papadopoulos, T. Costopoulos, Experimental investigation of load sharing in multiple gear tooth contact using the stress-optical method of caustics, Strain, T. 47. No. SUPPL. 1, Pp. 227-233 (2011)

9. N.R. Tailor, V.V. Kuzin, Model of tensely deformed condition of the surface layer of ceramic if abrazivostruynoy abrasive jet processing, Vestnik MSTU Stankin, No. 1 (36), Pp. 59-63 (2016)

10. V.D. Atanasov, I.I. Dement'ev, S.A. Nemykin, B.I. Poletaev, Mathematical models of intense-deformed 
ostoyaniye elastic elements of aircraft structures, Bulletin of the Russian Academy of rocket and artillery Sciences, No. 2, Pp. 71-75 (2015)

11. V.V. Glagolev, V. L. Glagolev, A. A. Markin, Stress-strain state of elastoplastic bodies with crack. Acta Mechanica Solida Sinica, T. 28. No. 4, Pp. 375-383 (2015)

12. S.V. Reznik, P.V. Prosuntsov, A.V. Azarov, Modelling of the temperature and stressed-strained states of the mirror a reflector of space antenna, Journal of Engineering Physics and Thermophysics, T.88. No. 6, Pp. 978-983 (2015)

13. V.V. Murav'ev, L.V. Volkova, A.V. Platunov, V.A. Kulikov, An electromagnetic-acoustic method for studying stress-strain states of rails, Russian Journal of Non-destructive Testing, Vol. 52, No. 7, Pp. 370376 (2016)

14. I.P. Miroshnichenko, V.P. Sizov, Definition of stress-strain state of layered anisotropic elliptic construction under action of impulse load, Journal: Advanced Materials Studies and Applications. Ser. "Nanotechnology Science and Technology", Pp. 353-390 (2015)

15. Yu.K. Mashkov, Zn. Shepherd, M. Y. Baibaratskaya, O. A. Mamaev, Polymeric composites materials in tribology (M., 2004)

16. G.M. Sorokin, Tribology of steels and alloys (M.: Nedra, 2000)

17. D.N. Garkunov, Tribology (M.: publishing house of ICCA, 2001)

18. V.M. Khokhlov, Design of wear-resistant friction units of sliding (VIMAGE, Bryansk, 2000)

19. G.M. Sorokin, Problems of metallurgy and tribology in petroleum engineering.. Izv. Universities, The oil and gas, No. 4, Pp. 21-24 (2003)

20. R.N. Suleymanov, A.S. Galeev, G.I. Bikbulatov, Overall performance of pumping aggregates (Ufim. state petroleum University, Ufa T., 2004)

21. A.K. Shekunov, V.A. Vasilchenko, Regulating hydrodevices for hydraulic systems of oil-field machines and an oil and gas complex petroleum engineering, Oil and gas mechanical engineering, No. 7, Pp. 74-75 (2004)

22. A.V. Chichinadze, E.M. Berliner, E.D. Brown, M. etc., Friction, wear and lubrication, Tribology and tribotechnics (M., 2003)

23. V.N. Vinogradov, G.M. Sorokin, M.G. Kolokol'chikov, Abrasive wear (M.: Mechanical engineering, 1990)

24. P.I. Malenko, Acoustic spectroscopy of the processes of structure formation on the rubbing surfaces (Tul'skiy state university, Tula, 2002)

25. V.N. Prokop'ev, N.A. Usol'tcev, E.A. Zadorozhnaya, Fundamentals of tribology: text of lectures (South. - Urals. state. un-t. Chelyabinsk, 2001)
26. L. A. Timofeeva, L. V. Proskurin, V. N. Ostapchuk, S. S. Timofeeva, Management of conditions of antifrictional and frictional friction units, Heavy mechanical engineering, No. 3, Pp. 27-28 (2002)

27. S.V. Fedorov, Bases of triboengineering and physico-chemical prerequisites of the theory of compatibility (Kaliningr. state. tekh. un-t, Kaliningrad, 2003)

28. L.V. Krasnichenko, Tribotechnical properties of friction pairs reverse, Vestn. Donskoy state. tekh. University, T.3, No.3. Pp. 281-292 (2003)

29. V.G. Novikov, A.V. Zharov, Tribology, Friction of metals and elastomers: [studies benefit] (Yarosl. state. tekh. university, dep. internal combustion engines; Yaroslavl, 2004)

30. V.A. Vlasov, Research of influence of high normal pressures on frictional properties of elastomers, Machines and technology of conversion of rubbers, polymers and rubber mixes. - Yaroslavl, Pp. 10-12. (1981) 